\title{
In-Vivo Effectiveness of 5\% Azadirachta indica Oil Cream as Anti-Scabies
}

\author{
Patihul Husni, Mayang Kusuma Dewi, Norisca Aliza Putriana, Rini Hendriani \\ Department of Pharmaceutics and Pharmaceutical Technology, Faculty of Pharmacy, \\ Padjadjaran University, Bandung, West Java, Indonesia
}

\begin{abstract}
Scabies is an infectious skin disease caused by mite Sarcoptes scabiei. Neem tree (Azadirachta indica) has the potential to be used as an anti-parasite due to the presence of azadirachtin compound that is commonly found in the seeds. The aim of this study was to evaluate in-vivo effectiveness of neem oil as an anti-scabies. This study used an experimental method. The effectiveness of the cream as an anti-scabies was tested on New Zealand white rabbits which were infected with scabies. Permethrin cream was used as a positive control and cream base was used as a negative control. Cream was applied once daily and left for 8 hours. The data were analyzed using Kruskal Wallis and Mann Whitney. Dermal acute irritation test was performed by applying $0.5 \mathrm{~g}$ cream on the rabbit dorsal. We found that $5 \%$ neem oil cream was effective as an anti-scabies with 20-21 days recovery time. The recovery time is longer than permethrin cream (7-8 days), but shorter compared to negative control with recovery time over 30 days. Primary irritation index for $5 \%$ neem oil creams was 0 , indicating negligible irritation category. In conclusion, $A$. indica cream was effective for the treatment of scabies although its recovery time is shorter than permethrin cream.
\end{abstract}

Keywords: effectiveness test, irritation test, neem oil cream, scabies

\section{Introduction}

Scabies is a contagious skin disease caused by mites Sarcoptes scabiei. The infection cause erythema, papules, and vesicles which can lead to skin damage. Itching usually occurs at night. $S$. scabiei is an obligate parasite whose breeding requires a host. Scabies affects many children. Transmission can occur through direct contact with people with scabies or through indirect contact, such as the use of same clothing, towels, etc. Dense population with poor hygiene level can facilitate transmission of scabies. Indonesia is one of the five countries with the highest prevalence of scabies. ${ }^{1,2}$ Scabies can be treated through systemic and topical therapy. However, systemic treatmet is only given for severe scabies. Thus, topical therapy is the main treatment choice for scabies. ${ }^{3,4}$

Neem tree (A. indica) is a medicinal plant originating from India. Neem tree can grow well in tropical and subtropical areas. Every part of this plant has its own function that can be used for empirical treatment. This

Corresponding author: Patihul Husni. Department of Pharmaceutics and Pharmaceutical Technology, Faculty of Pharmacy, Padjadjaran University, Bandung, West Java, Indonesia. Email: patihul.husni@unpad.ac.id

Received: 14 December 2018. Revised: 25 March 2019. Published: 25 April 2019. 
plant has many biological activities, e.g., as anti-histamines, anti-dermatitis, anti-fungi, anti-inflammatory, anti-scabies, diuretics, insecticides, anti-protozoa, spermicidal, and other biological activities. Previous study found that there was no difference in the effectiveness of the cream containing $10 \%$ of neem oil and $5 \%$ of permethrin cream as positive control for scabies. ${ }^{5,6}$ There is an urgent need to further evaluate the effectiveness of neem oil at different concentration with in-vivo method. In-vivo evaluation needs to be conducted to ensure the safety and effectiveness of the cream before being clinically tested in humans. Skin irritation potential also should be investigated to obtain complete safety profile of the cream. $^{7}$ Therefore, we conducted this study to evaluate in-vivo safety and effectiveness of neem oil as an antiscabies.

\section{Methods}

This study used an experimental method. The procedures in this study included cream formulation, acclimatization of test animals, acute dermal irritation test, and anti-scabies effectiveness test. The conduct of this study was approved by the Health Research Ethics Commission of the Faculty of Medicine, Padjadjaran University, Indonesia (No. 881/ UN6.C.10/PN/2017).

\section{Cream formulation}

Certificated neem oil which was obtained from Happy Green Co, Jakarta, Indonesia. The cream was formulated: $5 \%$ neem oil, $1 \mathrm{~g}$ adeps lanae, $14.2 \mathrm{~g}$ stearic acid, $10 \mathrm{~g}$ glycerin, $0.25 \mathrm{~g}$ sodium tetraborate, $1 \mathrm{~g}$ triethanolamine, $75 \mathrm{~g}$ distilled water, and $0.1 \%$ nipagine. The oil phase (adeps lanae and stearic acid) was placed in a vaporizer dish and heated over a waterbath at $70^{\circ} \mathrm{C}$. The water phase (glycerin, sodium tetraborate, triethanololamine and distilled water) was placed in the evaporator cup and heated under the same conditions.
The oil and water masses were mixed at the same temperature until cream was formed. Nipagin was dissolved in distilled water and then mixed into the cream. Neem oil was added to the base cream. The cream was then mixed until homogenous. ${ }^{9,10}$

\section{Acclimatization of the animals}

The experimental animals used were New Zealand albino male rabbits (6-8 weeks) with the weight of 1.5-2 kilograms. The animals were normally fed and maintained in a room with good air circulation, temperature, and lighting. The animals were acclimatized for 5 days. The body weight of the animals were observed every day. The animals that lost more than $10 \%$ of their body weight during acclimatization were excluded. ${ }^{8}$

\section{Acute irritation test}

A dermal acute irritation test was performed on healthy skin. Animal hair was shaved on the back area $(2 \times 3 \mathrm{~cm})$. An irritation test was performed by applying $0.5 \mathrm{~g}$ of cream on the dorsal. It was then covered with gauze and plaster. The animals were divided into 2 group, i.e., control formula (base) and 5\% neem oil cream. Each group has 3 animals. The degree of irritation was assessed after 1 hour, 24, 48, and 72 hours after exposure. ${ }^{11}$ Primary irritation index was calculated with the following formula:

Primary Irritation Index $=(A-B)$

Information:

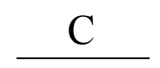

A: The number of erythema and udema in tested observation area after 24, 48 and 72 hours divided by the number of observations. B: The number of erythema and udema in control observation area after 24, 48 and 72 hours divided by the number of observations. $\mathrm{C}$ : Number of animals 
Table 1. Irritation Response Category on Rabbit ${ }^{9}$

\begin{tabular}{cc}
\hline Average & Category \\
\hline $0.0-0.4$ & Negligible \\
$0.5-1.9$ & Slight \\
$2.0-4.9$ & Moderate \\
$5.0-8.0$ & Severe \\
\hline
\end{tabular}

Anti-scabies effectiveness test

The $S$. scabei were injected to the back skin of animal. The transmission was performed indirectly, i.e., by swabing the rabbit dorsal infected with scabies into gauze and then affixed to the back of the test animal using plester. The incubation period of $S$. scabiei is 14 days from eggs to adult mites. Thus, the rabbit is left 2-3 weeks until the parasites spreads evenly to the surface of the skin.

The effectiveness of anti-scabies cream was calculated using the Federer formula. ${ }^{11,12}$ New Zealand male rabbits were divided into 3 groups, i.e, the test group (5\% neem oil cream), the positive control ( $5 \%$ permetherin cream), and the negative control group (cream base). The effectiveness of the cream was performed on rabbits infected with scabies by applying the cream to the infected skin once a day and left for 8 hours before it was cleaned.
Observations were conducted every day for 1 month. Examination of wound healing was conducted by observing the wound closure. Score of 1-5 was given in each observation (Table 3). Data analysis was performed using the Kruskal Wallis test and the Mann Whitney test. The Kruskal Wallis test was used to examine value differences in more than two groups. The Mann Whitney test was used to evaluate significant differences between categories.

\section{Results and Discussion}

\section{Cream formulation}

$5 \%$ neem oil cream had thick consistency, faded yellow white co, distinctive odor, $\mathrm{pH}$ 8 , and viscosity around $4195 \mathrm{Cps}$. Cream was selected as a dosage form since it has good ability to spread on the skin surface and is more convenient for the animals. The $\mathrm{pH}$ value was within the recommended

Table 2. Assessment of Skin Reactions ${ }^{10}$

\begin{tabular}{lc}
\hline Erythema & Score \\
\hline There is no erythema & 0 \\
Very small erythema (almost indistinguishable) & 1 \\
Erythema is clearly visible & 2 \\
Moderate to severe erythema & 3 \\
Severe erythema (flesh red) to eschar formation which inhibits erythematous assessment & 4 \\
\hline Edema & Score \\
\hline There is no edema & 0 \\
Edema is very small (almost indistinguishable) & 1 \\
Small edema (visible area boundary) & 2 \\
Mid-level edema (increase in area by about $1 \mathrm{~mm}$ ) & 3 \\
Severe edema (the area increases more than $1 \mathrm{~mm}$ and widens beyond the exposure area) & 4 \\
\hline
\end{tabular}


Table 3. Assessment of the Effectiveness of the Cream $1^{1}$

\begin{tabular}{clc}
\hline No & \multicolumn{1}{c}{ Assesment } & Score \\
\hline 1 & The wound closes 100\% (the wound closes completely and has no scab) & 1 \\
2 & The wound closes 75\% (the wound closes and has few scabs) & 2 \\
3 & The wound closes 50\% (the wound partially closes and has few scabs) & 3 \\
4 & The wound closes 25\% (the wound slightly closes and has many scabs) & 4 \\
5 & The wound completely opens and has many scabs & 5 \\
\hline
\end{tabular}

range based on the Regulation of the Head National Agency of Drug and Food Control No.7/2014. Cream should not be administered to the skin if it has extreme $\mathrm{pH}$ $(\mathrm{pH} \leq 2 \text { or } \geq 11.5)^{8}$

\section{Dermal acute irritation test}

The irritation test aimed to evaluate the safety of the neem oil cream by observing the the level of eryhtma and edema. Albino rabbit was selected as it has sensitive skin. Beside, the color of skin is brighter than the other type of rabbits. These characteristics allowed straightforward observation on the skin irritation. The primary irritation index for $5 \%$ neem oil cream is 0 , indicating very negligible irritation category (a range of 0.0 $0.4)$. Thus, it was safe to be applied to the skin.

\section{Anti-scabies effectiveness}

We found that $5 \%$ neem oil was effective as an anti-scabies with 20-21 days recovery time (Table 4 and 5). The recovery time is longer than permethrin cream (7-8 days), but shorter compared to negative control with recovery time over 30 days. Statistical analysis showed that there was significant difference between three dose groups. Azadirachtin compound in neem oil acted as an anti-parasites. This compound affects the hormonal cycle of parasites, prevents the growth and development of mites, makes the eggs sterile, and gives an antifeedant effect. ${ }^{9-14}$ Neem oil does not terminate scabies mites directly, but interfere with the proliferation and reproduction of mites, thus there is a reduction in the population of parasites over time. Therefore, the application of the cream should be conducted daily. Besides, the cream can also relieve itching and moisturize cracked skin. ${ }^{15,16}$

The 5\% permethrin cream was used as the positive control because it is the first line of anti-scabies drugs. Permethrin cream has very low toxicity to mammals but the results of in vivo studies showed children are more sensitive to permethrin. ${ }^{1,16}$ Besides, it has very little absorption and was metabolized quickly. It was excreted through sweat, sebum, and urine. ${ }^{17-19}$ Nevertheless, its recovery time is shorther than neem oil.

This study has limitation, particularly in the transmission process of $S$. scabiei. The administration of parasites on rabbit dorsal

Table 4. Comparison of Recovery Times

\begin{tabular}{lccc}
\hline \multicolumn{1}{c}{ Group } & Average (day) & p-value & \\
\hline $5 \%$ neem oil cream & $20.75 \pm 1.71$ & & \\
$5 \%$ permethrin cream & $7.50 \pm 0.58$ & 0.000 & Significant difference \\
cream base & $31.00 \pm 0.00$ & & \\
\hline
\end{tabular}


parts is relatively difficult. Besides, we did not perform the assessment to evaluate the spread of scabies in the dorsal skin. Microscopic testing with the use of $10 \%$ $\mathrm{KOH}$ as keratolytic could be conducted. ${ }^{20}$

\section{Conclusion}

A. indica oil cream was effective for the treatment of scabies although its recovery time is shorter than permethrin cream.

\section{Acknowledgements}

None declared.

\section{Funding}

This research was funded by the 2017 Padjadjaran University Internal Grant.

\section{Conflict of Interest}

None declared.

\section{References}

1. Banerji A. Scabies. Paediatric and Child Health. 2015;20(7):395-402.

2. Mading M, Sopi IIPB, Epidemiology study of scabies on human. Journal of Animal-Borne Diseases. 2015;2(2):9-17.

3. Karimkhani C, Colombara DV, Drucker AM, et al. The global burden of scabies: a cross-sectional analysis from the global burden of disease study 2015. Lancet Infectious Disease. 2017;17(12):12471254.

4. Hashmat IH, Azad H, Ahmed A. Neem (Azadirachta indica A. Juss) a nature's drugstore: An overview. Research Journal of Biological Science. 2012;1(6):76-79.

5. Pankaj S, Lokeshwar T, Mukesh B. Review on neem (Azadirachta indica): thousand problems one solution. International Research Journal of Pharmacy. 2011;2(12): 97-102.

6. Zainal N, Tabri F, Muchtar SV, et al. Effectivenes of $10 \%$ neem oil on scabies paeints. JST Health. 2013;3: 196-202.
7. Chang R, Raw A, Lionberger R. Generic development of topical dermatologic products: Formulation development, process development, and testing of topical dermatologic products. American Association of Pharmaceutical Scientists. 2013;15(1):41-52.

8. Indonesia National Agency of Drugs and Food Control. Regulation of Head of NADFC No. 7/2014 about the guideline of in-vivo toxicity testing. Jakarta: BPOM RI; 2014.

9. International Standard ISO 10993-10. Biological evaluation of medical devices - part 10: tests for irritation and delayedtype hypersensitivity, second edition. 2002.

10. Zanuncio JC, Mourão SA, Martínez $\mathrm{LC}$, et al. Toxic effects of the neem oil (Azadirachta indica) formulation on the stink bug predator, Podisus nigrispinus (Heteroptera: Pentatomidae). Scientific Reports. 2016;6:30261.

11. Luo B, Liao F, Hu Y, et al. Acaricidal activity of extracts from Ligularia virgaurea against the Sarcoptes scabiei mite in vitro. Experimental and Therapeutic Medicine. 2015;10(1):247250.

12. Charan J, Kantharia ND. How to calculate sample size in animal studies? Journal of Pharmacology and Pharmacotherapy. 2013;4(4):303-306.

13. Ahn J, Eum K, Lee M. Assessment of the dermal and ocular irritation potential of lomefloxacin by using in vitro methods. Toxicology Research. 2010;26(1):9-14.

14. Alzohairy MA. Therapeutics role of Azadirachta indica (Neem) and their active constituents in diseases prevention and treatment. EvidenceBased Complementary and Alternative Medicine. 2016;1:1-11.

15. Lima DB, Melo JWS, Guedes NMP, et al Bioinsecticide-predator interactions: 
azadirachtin behavioral and reproductive impairment of the coconut mite predator Neoseiulus baraki. Plos One. 2015;10(2):1-13.

16. Drago B, Shah NS, Shah SH. Acute permethrin neurotoxicity: Variable presentations, high index of suspicion. Toxicology Reports. 2014;1:1026-1028.

17. Wang X, Martinez MA, Dai M, et al. Permethrin-induced oxidative stress and toxicity and metabolism. A review. Environmental Research. 2016;149:86104.

18. Willemin ME, Kadar A, de Sousa G, et al In vitro human metabolism of permethrin isomers alone or as a mixture and the formation of the major metabolites in cryopreserved primary hepatocytes. Toxicology In Vitro. 2015;29(4):803-12.

19. Hedges L, Brown S, MacLeod AK, et al. Metabolism of deltamethrin and cis- and trans-permethrin by human expressed cytochrome P450 and carboxylesterase enzymes. Xenobiotica. 2018;4:1-7.

20. Jayaprasad S, Subramaniyan R, Devgan S. Comparative evaluation of topical $10 \%$ potassium hydroxide and $30 \%$ trichloroacetic acid in the treatment of plane warts. Indian Journal of Dermatology. 2016;61(6):634-639. 